\title{
Combination therapy of ipilimumab and nivolumab induced thyroid storm in a patient with Hashimoto's disease and diabetes mellitus: a case report
}

\author{
Kazuko Yonezaki, Toshihiro Kobayashi", Hitomi Imachi, Takuo Yoshimoto, Fumi Kikuchi, Kensaku Fukunaga, \\ Seisuke Sato, Tomohiro Ibata, Nao Yamaji, Jingya Lyu, Tao Dong and Koji Murao*
}

\begin{abstract}
Background: Recently, immune checkpoint inhibitors have widely been used for the management of advanced melanoma. However, high-grade immune-related adverse events can occur, particularly with combination immunotherapy. We report a case of a patient with melanoma who developed thyroid storm following treatment with ipilimumab and nivolumab.

Case presentation: An 85-year-old Japanese man with a history of malignant melanoma presented to our department with severe thyrotoxicosis and poor blood glucose control. He was already being treated for Hashimoto's disease and type 2 diabetes mellitus before the treatment for the melanoma. During admission, laboratory investigations revealed the following thyroid functions: thyroid-stimulating hormone below sensitivity, free triiodothyronine $31.7 \mathrm{pg} / \mathrm{ml}$, and thyroglobulin $48,000 \mathrm{IU} / \mathrm{ml}$. Thyroid-stimulating hormone receptor antibody was negative, and a ${ }^{99 m}$ Tc-labeled thyroid scan revealed a markedly decreased uptake. He was treated with beta-blocker, orally administered potassium iodine, a relatively low dose of prednisolone, and insulin injection therapy to control his blood glucose, resulting in an improvement in thyroid function and his symptoms.

Conclusion: It might be important to be aware of the possibility of thyroid storm induced by immune checkpoint inhibitors.
\end{abstract}

Keywords: Thyroid storm, Immune checkpoint inhibitor, Hashimoto's disease

\section{Background}

Thyroid storm is an acute, life-threatening state induced by excessive release of thyroid hormones in individuals with thyrotoxicosis. The clinical symptoms include fever, tachycardia, and neurological and gastrointestinal (GI) abnormalities. Diagnosis is dependent on clinical symptoms, and no specific laboratory tests are available. Many factors including some drugs may precipitate the progression of thyrotoxicosis to thyroid storm [1]. In thyroid storm, a patient's heart rate, blood pressure, and body temperature can get to dangerously high levels. Without prompt treatment, thyroid storm is often fatal.

\footnotetext{
* Correspondence: koba1987@med.kagawa-u.ac.jp; mkoji@med.kagawa-u.ac.jp Department of Endocrinology and Metabolism, Faculty of Medicine, Kagawa University, 1750-1, Miki-cho, Kita-gun, Kagawa 761-0793, Japan
}

Immune checkpoint inhibitors are widely used for the management of advanced melanoma. These include ipilimumab to block the negative checkpoint regulator cytotoxic T-lymphocyte antigen-4 (CTLA-4) on the surface of activated $\mathrm{T}$ cells [2]. Other immune checkpoint inhibitors were developed, including pembrolizumab and nivolumab; both of these immune checkpoint inhibitors are immunoglobulin G4 (IgG4) monoclonal antibodies that target the programmed cell death protein 1 (PD-1), which is a negative regulatory $\mathrm{T}$ cell surface receptor [3]. During the development of these immune checkpoint inhibitors, it was quickly recognized that the immune checkpoint inhibitors were associated with a novel syndrome of

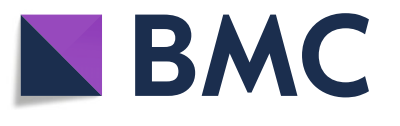

(c) The Author(s). 2018 Open Access This article is distributed under the terms of the Creative Commons Attribution 4.0 International License (http://creativecommons.org/licenses/by/4.0/), which permits unrestricted use, distribution, and reproduction in any medium, provided you give appropriate credit to the original author(s) and the source, provide a link to the Creative Commons license, and indicate if changes were made. The Creative Commons Public Domain Dedication waiver (http://creativecommons.org/publicdomain/zero/1.0/) applies to the data made available in this article, unless otherwise stated. 
autoimmune or autoinflammatory side effects [4]. These toxicities have become known as immune-related adverse events (irAEs) and occur more frequently when these agents are administered in combination regimens [5]. In this report, we present a very rare case of thyroid storm in a patient with advanced melanoma receiving dual ipilimumab and nivolumab therapy and discuss the clinical presentation and therapeutic interventions in a patient with Hashimoto's disease and type 2 diabetes mellitus.

\section{Case presentation}

An 85-year-old Japanese man with a history of malignant melanoma of the nasal cavity presented to our department with severe thyrotoxicosis and poor blood glucose control. He had been treated for hypothyroidism secondary to Hashimoto's disease and type 2 diabetes mellitus with insulin self-injection therapy before undergoing treatment of malignant melanoma. A surgical operation of his nasal cavity was done at first, followed by one of four planned cycles of nivolumab therapy. Subsequently, two courses of ipilimumab were given as standard therapy after nivolumab therapy. Two weeks later after receiving a dual course of ipilimumab as a third treatment, he presented with a fatigue, nausea, and sweating, which progressed to clinical and biochemical thyrotoxicosis. On admission to our hospital, he was febrile with a temperature of $38.0{ }^{\circ} \mathrm{C}$, tachycardic, agitated, and acutely anxious but still conscious (restlessness). His Glasgow Coma Scale score was 14/15. His blood pressure had decreased to $70 / 50 \mathrm{mmHg}$.

His physical examination revealed a diffuse goiter without exophthalmoses. His abdomen was soft and non-tender and his skin was warm and wet. He was also diaphoretic with jugular venous distension and peripheral edema, and his chest was clinically clear. His medical history included hypothyroidism due to Hashimoto's disease, diagnosed at 62 years of age and treated with thyroid hormone replacement, as well as type 2 diabetes mellitus treated by self-injection of insulin with a good glycemic control. He had both family histories of thyroid diseases and diabetes. An electrocardiogram showed marked tachycardia with atrial fibrillation, but a chest radiograph was normal.

The laboratory data are shown in Table 1. Laboratory investigation revealed the following thyroid function results: thyroid-stimulating hormone (TSH) below sensitivity, free triiodothyronine (FT3) $31.7 \mathrm{pg} / \mathrm{ml}$, and free thyroxine (FT4) $3.43 \mathrm{ng} / \mathrm{dl}$. Remarkably, his thyroglobulin was elevated to $48,000 \mathrm{IU} / \mathrm{ml}$. TSH receptor antibody was negative, and a ${ }^{99 \mathrm{~m}}$ Tc-labeled thyroid scan revealed a markedly decreased uptake (Tc retention index-uptake ratio $0.0 \%$; normal range $0.4-3.0$ ). His blood glucose was markedly elevated; in which case, we needed to increase the amount of insulin to control his blood glucose.
Further immunological investigation revealed normal serum levels of anti-glutamic acid decarboxylase (GAD) antibody, anti-insulinoma antigen 2 (IA-2) antibody, and insulin autoantibody (IAA).

According to the diagnostic criteria of the Japan Thyroid Association for thyroid storm [1], he was diagnosed as having thyroid storm 1 (TS1), definite thyroid storm, since he had thyrotoxicosis, a central nervous system symptom (restlessness), fever $\left(38{ }^{\circ} \mathrm{C}\right)$, GI symptoms (nausea, vomiting), and tachycardia (135 beats per minute) in atrial fibrillation. Based on the diagnostic criteria of Burch and Wartofsky for thyroid storm, he scored 60; a score higher than 45 is suggestive of thyroid storm [6]. Graves' disease was less likely as thyroid-stimulating immunoglobulin was within the normal range, and ${ }^{99 \mathrm{~m}}$ Tc-scintigraphy revealed a quite low uptake. These results indicated that his diagnosis of thyroid storm was due to destructive thyroiditis.

His clinical course is shown in Fig. 1. He was treated with an intravenously administered insulin infusion and intravenously administered fluid therapy. At first, the thyroid storm was treated with orally administered potassium iodide (50 mg every 6 hours) and a short-acting beta-adrenoreceptor blocker, landiolol hydrochloride, was used at $4-10 \mu \mathrm{g} / \mathrm{kg}$ per minute to control his heart rate. The potassium iodide was aborted when he was diagnosed as having distractive thyroiditis. Prednisolone was given at $0.5-0.7 \mathrm{mg} / \mathrm{kg}$ per day as a treatment for irAE and thyroid storm. Although previous reports suggested the optimum dosage of prednisolone to be $1-2 \mathrm{mg} / \mathrm{kg}$ per day $[1,5]$, we used a lower dose due to the coexisting and uncontrolled diabetes mellitus. By day 5, his tachycardia had resolved, and the landiolol hydrochloride was discontinued. On day 11, his thyroid function was found to have improved, and the amount of total insulin used to control his blood glucose was decreased. On day 25 , he was found to have hypothyroidism, and so we restarted the replacement of thyroid hormone. He was discharged from our hospital on day 35 on daily maintenance insulin injection and levothyroxine sodium hydrate.

\section{Discussion}

Thyroid storm is an endocrine emergency that is characterized by rapid deterioration within days or hours of presentation and is associated with a high mortality [1]. Most cases of thyroid storm are caused by the presence of some triggering condition in conjunction with an underlying thyroid condition. This usually involves untreated or uncontrolled Graves' disease, but may rarely be due to thyrotoxic disorders such as toxic multinodular goiters, TSH-secreting pituitary adenomas, human chorionic gonadotropin (hCG)-secreting hydatidiform moles, metastatic thyroid cancers, and destructive thyroiditis [1]. Thyroid storm is precipitated by many 
Table 1 A summary of laboratory data

\begin{tabular}{|c|c|c|}
\hline Blood chemistry & & Reference \\
\hline C-reactive protein (mg/dl) & 11.6 & $\leq 0.20$ \\
\hline Sodium (mmol/L) & 135 & $135-146$ \\
\hline Potassium (mmol/L) & 3.9 & $3.5-4.6$ \\
\hline Chloride (mmol/L) & 101 & $96-110$ \\
\hline Calcium (mg/dl) & 8.9 & $8.2-10.2$ \\
\hline Phosphorus (mg/dl) & 3.0 & $2.5-5.5$ \\
\hline Blood urea nitrogen (mg/dl) & 38.3 & $7.0-20.0$ \\
\hline Creatinine $(\mathrm{mg} / \mathrm{dl})$ & 0.85 & $0.7-1.3$ \\
\hline eGFR (ml/minute) & 51.9 & $\geq 60.0$ \\
\hline Total protein (g/dl) & 6.1 & $6.5-8.2$ \\
\hline Albumin (g/dl) & 2.8 & $3.5-5.5$ \\
\hline Total bilirubin (mg/dl) & 0.6 & $0.1-1.2$ \\
\hline Aspartate aminotransferase $(\mathrm{U} / \mathrm{L})$ & 33 & $10-35$ \\
\hline Alanine aminotransferase $(U / L)$ & 34 & $5-40$ \\
\hline Alkaline phosphatase $(U / L)$ & 245 & $100-340$ \\
\hline Lactate dehydrogenase $(\mathrm{U} / \mathrm{L})$ & 284 & $110-220$ \\
\hline$y$-Glutamyl transpeptidase $(U / L)$ & 12 & $\leq 60$ \\
\hline Creatine kinase $(U / L)$ & 132 & $40-200$ \\
\hline Blood count & & Reference \\
\hline Red blood cell $\left(\times 10^{4} / \mu \mathrm{L}\right)$ & 341 & $427-570$ \\
\hline Hemoglobin (g/dl) & 10.7 & $13.5-17.6$ \\
\hline Hematocrit (\%) & 31.0 & $39.8-51.8$ \\
\hline MCV (fl) & 90.9 & 82.7-101.6 \\
\hline Platelet $\left(\times 10^{4} / \mu \mathrm{L}\right)$ & 23.7 & $13.1-36.2$ \\
\hline White blood cell $(\mu \mathrm{L})$ & 13,380 & $3900-9800$ \\
\hline Neutrophil counts $(\mu \mathrm{L})$ & 11,600 & \\
\hline Diabetes & & Reference \\
\hline Glucose (mg/dl) & 142 & $70-109$ \\
\hline Hemoglobin A1c (\%) & 6.7 & $4.7-6.2$ \\
\hline $\mid \mathrm{RI}(\mu \mathrm{U} / \mathrm{ml})$ & 102.1 & $3.0-18.0$ \\
\hline CPR (ng/ml) & 0.63 & $0.6-1.8$ \\
\hline GAD antibody & $\leq 5.0$ & $\leq 5.0$ \\
\hline IA-2 antibody & $\leq 0.4$ & $\leq 0.4$ \\
\hline Urinary albumin $(\mathrm{mg} / \mathrm{gCr})$ & 281.0 & \\
\hline Thyroid & & Reference \\
\hline Free triiodothyronine (pg/ml) & 31.7 & $2.2-4.1$ \\
\hline Free thyroxine $(\mathrm{ng} / \mathrm{dl})$ & 3.43 & $0.88-1.81$ \\
\hline Thyroid-stimulating hormone $(\mu \mathrm{l} \mathrm{U} / \mathrm{ml})$ & 0.128 & $0.35-3.73$ \\
\hline TSH receptor antibody (IU/L) & 0.51 & $<2.0$ \\
\hline Thyroid stimulating antibody (\%) & 102 & $\leq 120$ \\
\hline Thyroglobulin (ng/ml) & 48,000 & $\leq 33.70$ \\
\hline Thyroglobulin antibody (IU/ml) & 457 & $<28$ \\
\hline Thyroid peroxidase antibody (IU/ml) & 8.0 & $<16$ \\
\hline
\end{tabular}

Table 1 A summary of laboratory data (Continued)

\begin{tabular}{lll}
\hline Endocrine & & Reference \\
Cortisol $(\mu \mathrm{g} / \mathrm{dl})$ & 27.5 & $4.5-21.1$ \\
Growth hormone $(\mathrm{ng} / \mathrm{ml})$ & 0.13 & $\leq 2.47$ \\
Somatomedin C $(\mathrm{ng} / \mathrm{ml})$ & 39 & $48-177$ \\
Luteinizing hormone $(\mathrm{mlU} / \mathrm{ml})$ & 18.8 & $0.8-5.7$ \\
Follicle-stimulating hormone $(\mathrm{mlU} / \mathrm{ml})$ & 5.8 & $2.0-8.3$ \\
Free testosterone $(\mathrm{pg} / \mathrm{ml})$ & 11.0 & $4.6-16.9$ \\
Prolactin $(\mathrm{ng} / \mathrm{ml})$ & 9.6 & $3.6-12.8$ \\
Antidiuretic hormone $(\mathrm{pg} / \mathrm{ml})$ & 2.7 & $\leq 2.8$ \\
\hline
\end{tabular}

CPR C-peptide immunoreactivity, eGFR estimated glomerular filtration rate, $G A D$ glutamic acid decarboxylase, $I A-2$ islet antigen 2, IRI immunoreactive insulin, MCV mean corpuscular volume, TSH thyroid-stimulating hormone

factors, such as the irregular use or discontinuation of antithyroid drugs, infection, diabetic ketoacidosis, surgery, radioiodine therapy, adrenocortical insufficiency, and the administration of iodinated contrast agents. In addition, several drugs that cause thyrotoxicosis as an adverse event, including amiodarone, sorafenib, and ipilimumab, have been reported to precipitate thyroid storm [7, 8]. It is important to point out that our patient was treated with amiodarone for 1 year prior to the initiation of nivolumab and ipilimumab. Amiodarone has been associated with thyroid dysfunction; amiodarone was aborted when the patient was admitted to our hospital. Our patient had thyroid function testing that was within normal range prior to the initiation of nivolumab and ipilimumab; however, we could not have ruled out the possibility that the thyroid storm was precipitated by the treatment of amiodarone. A previous case report of thyroid storm caused by combination therapy with ipilimumab and nivolumab was published [9]. On the other hand, $\mathrm{Yu}$ et al. also reported a case of thyroid storm in a patient receiving immunotherapy for melanoma with ipilimumab alone [10]. Destructive thyroiditis is more frequent and severe with the combination of ipilimumab and nivolumab compared with ipilimumab monotherapy, but still remains rare $(<1 \%)$ with both regimens. Since the evaluation of thyroid function is not routinely performed in most immunotherapy trials, the true incidence is unknown.

Combined immune checkpoint inhibition with ipilimumab and nivolumab produces frequent and durable anti-tumor responses in patients with advanced melanoma and has demonstrated promising activity in other cancers [11]. IrAEs, however, frequently complicate therapy, requiring cessation of therapy in nearly $40 \%$ of patients $[11,12]$. These events are generally managed with high-dose glucocorticoids although clinically severe, prolonged, and even fatal events rarely occur. Therefore, identifying these severe toxicities is a major priority, even for uncommon events. 


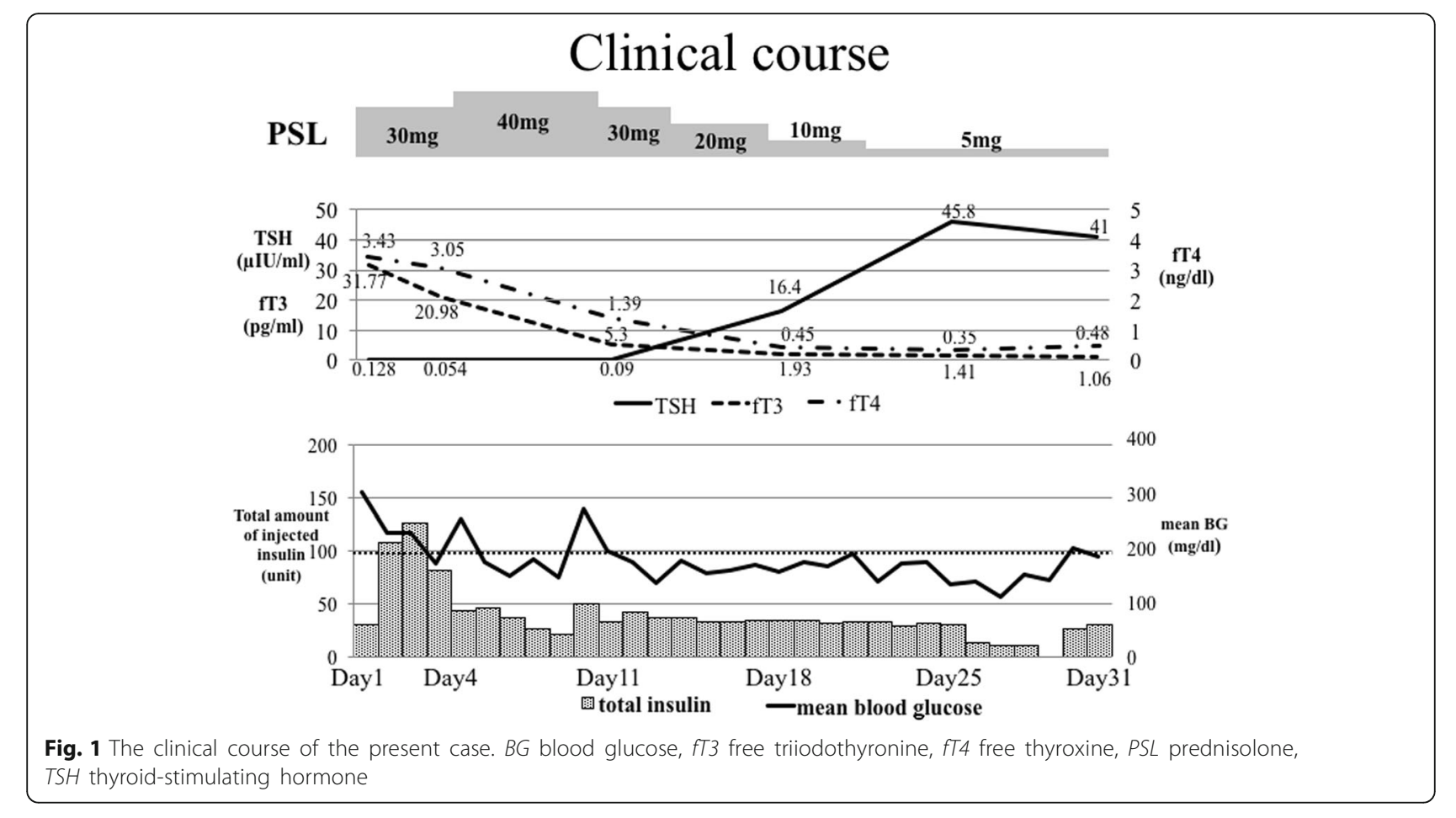

Morganstein et al. reported the rates of overt thyroid dysfunction in the published phase 3 trials involving ipilimumab and/or nivolumab [13]. Of the 18 patients treated with the combination of ipilimumab and nivolumab, four patients $(22.2 \%)$ developed hypothyroidism, one of whom had a preceding episode of hyperthyroidism, and two had preceding subclinical hyperthyroidism, none of whom needed anti-thyroid drugs, and two of whom were treated with thyroxine (T4). One patient (5.6\%) had subclinical hypothyroidism, and a further four patients (22.2\%) had subclinical hyperthyroidism without subsequent hypothyroidism. Overall, $29.5 \%$ of patients developed thyroid abnormalities, with the lowest rate of $23 \%$ in those treated with ipilimumab and the highest rate of $50 \%$ in those treated with combination therapy. Thyroid abnormalities were more common in female patients. Although the majority of abnormalities did not require treatment, this still poses a resource burden in terms of the need for follow-up and repeated measurements of thyroid function. It is notable that the subsets of patients who develop hypothyroidism have a transient initial hyperthyroid phase (often subclinical), highlighting the need for the careful recognition and follow-up of those with thyroid abnormalities. On the other hand, several reports indicated that a few patients with hyperthyroidism due to Graves' disease, not destructive thyroiditis, have also been rarely reported to have received treatment with ipilimumab [14]. Methimazole appears to be efficacious in the treatment of such patients.
Corticosteroids should be administered as prophylaxis for the relative adrenal insufficiency caused by the hypermetabolic state in thyroid storm. Large doses of corticosteroids have been shown to inhibit both thyroid hormone synthesis and the peripheral conversion of $\mathrm{T} 4$ to triiodothyronine (T3) [15]. A high dose of steroid (prednisone at $1-2 \mathrm{mg} / \mathrm{kg}$ per day) has been recommended for the treatment of irAE with an immune checkpoint inhibitor [5]. In our case, we reduced the amount of steroid because our patient had uncontrolled diabetes on self-injection of insulin.

Some reports have described that cases of autoimmune diabetes, known as type 1 diabetes, have emerged in association with the use of the anti-PD-1 antibody therapies $[16,17]$. Autoimmune diabetes is characterized by the development of an adaptive immune response against specific $\beta$-cell antigens. Longitudinal studies in patients have shown that certain autoantibodies, such as anti-IAA, antiICA512, and anti-GAD65, define preclinical disease as they are present in the serum for years prior to the onset of symptoms [18]. Half of the previously reported patients who developed insulin-dependent diabetes after anti-PD-1 therapy likewise showed no detectable islet autoantibodies. The pathogenesis in these patients thus seems to differ at least partly from that of conventional autoimmune type 1 diabetes which involves islet autoantibodies. Ansari et al. found no correlation between IAA levels and the development of diabetes with blockade of the PD-1-PD-L1 pathway in mice, and some mice 
developed diabetes despite the apparent absence of autoantibodies [19]. In the present case, all results for islet autoantibodies were negative. However, the present case should not be like a type 1 diabetes mellitus. Although islet autoantibodies remained negative for 3 months after the onset of his symptoms, his insulin secretion improved back to previous levels before the initiation of treatment with checkpoint inhibitors. In this case, thyrotoxicosis induced by checkpoint inhibitors worsened his blood glucose control so that he needed more insulin injections.

\section{Conclusions}

Immune checkpoint inhibitors will be widely used for melanoma. It might be important to be aware of the possibility of thyroid storm induced by combination therapy of ipilimumab and nivolumab.

\section{Authors' contributions}

All authors contributed equally. All authors read and approved the final manuscript.

\section{Ethics approval and consent to participate}

This study is approved by the ethics committee of Faculty of Medicine, Kagawa University.

\section{Consent for publication}

Written informed consent was obtained from the patient for publication of this case report and any accompanying images. A copy of the written consent is available for review by the Editor-in-Chief of this journal.

\section{Competing interests}

The authors declare that they have no competing interests.

\section{Publisher's Note}

Springer Nature remains neutral with regard to jurisdictional claims in published maps and institutional affiliations.

Received: 6 February 2018 Accepted: 2 May 2018

Published online: 19 June 2018

\section{References}

1. Satoh T, Isozaki O, Suzuki A, Wakino S, Iburi T, Tsuboi K, et al. 2016 Guidelines for the management of thyroid storm from The Japan Thyroid Association and Japan Endocrine Society (First edition). Endocr J. 2016;63(12):1025-64. PubMed PMID: 27746415.

2. Pardoll DM. The blockade of immune checkpoints in cancer immunotherapy Nat Rev Cancer. 2012:12(4):252-64. PubMed PMID: 22437870.

3. Page DB, Postow MA, Callahan MK, Allison JP, Wolchok JD. Immune modulation in cancer with antibodies. Annu Rev Med. 2014;65:185-202. PubMed PMID: 24188664.

4. Chen TW, Razak AR, Bedard PL, Siu LL, Hansen AR. A systematic review of immune-related adverse event reporting in clinical trials of immune checkpoint inhibitors. Ann Oncol. 2015;26(9):1824-9. PubMed PMID: 25888611.

5. Horvat TZ, Adel NG, Dang TO, Momtaz P, Postow MA, Callahan MK, et al. Immune-Related Adverse Events, Need for Systemic Immunosuppression, and Effects on Survival and Time to Treatment Failure in Patients With Melanoma Treated With Ipilimumab at Memorial Sloan Kettering Cancer Center. J Clin Oncol. 2015;33(28):3193-8. PubMed PMID: 26282644.

6. Burch HB, Wartofsky L. Life-threatening thyrotoxicosis. Thyroid storm. Endocrinol Metab Clin N Am. 1993;22(2):263-77. PubMed PMID: 8325286.

7. Georges JL, Normand JP, Lenormand ME, Schwob J. Life-threatening thyrotoxicosis induced by amiodarone in patients with benign heart disease. Eur Heart J. 1992:13(1):129-32. PubMed PMID: 1577019.

8. Haraldsdottir S, Li Q, Villalona-Calero MA, Olencki TE, Kendra K, Ing SW. Case of sorafenib-induced thyroid storm. J Clin Oncol. 2013:31(16):262-4. PubMed PMID: 23610115.
9. McMillen B, Dhillon MS, Yong-Yow S. A rare case of thyroid storm. BMJ Case Rep. 2016:2016:10. PubMed PMID: 27090545

10. Yu C, Chopra IJ, Ha E. A novel melanoma therapy stirs up a storm: ipilimumab-induced thyrotoxicosis. Endocrinol Diabetes Metab Case Rep. 2015;2015:140092. PubMed PMID: 25759760.

11. Larkin J, Chiarion-Sileni V, Gonzalez R, Grob JJ, Cowey CL, Lao CD, et al. Combined Nivolumab and Ipilimumab or Monotherapy in Untreated Melanoma. N Engl J Med. 2015;373(1):23-34. PubMed PMID: 26027431.

12. Postow MA, Chesney J, Pavlick AC, Robert C, Grossmann K, McDermott D, et al. Nivolumab and ipilimumab versus ipilimumab in untreated melanoma. N Engl J Med. 2015;372(21):2006-17. PubMed PMID: 25891304.

13. Morganstein DL, Lai Z, Spain L, Diem S, Levine D, Mace C, et al. Thyroid abnormalities following the use of cytotoxic T-lymphocyte antigen-4 and programmed death receptor protein-1 inhibitors in the treatment of melanoma. Clin Endocrinol. 2017:86(4):614-20. PubMed PMID: 28028828

14. Azmat U, Liebner D, Joehlin-Price A, Agrawal A, Nabhan F. Treatment of Ipilimumab Induced Graves' Disease in a Patient with Metastatic Melanoma. Case Rep Endocrinol. 2016;2016:2087525. PubMed PMID: 26881150.

15. Bianco AC, Nunes MT, Hell NS, Maciel RM. The role of glucocorticoids in the stress-induced reduction of extrathyroidal 3,5,3'-triiodothyronine generation in rats. Endocrinology. 1987;120(3):1033-8. PubMed PMID: 3803308.

16. Gaudy C, Clévy C, Monestier S, Dubois N, Préau Y, Mallet S, et al. Anti-PD1 Pembrolizumab Can Induce Exceptional Fulminant Type 1 Diabetes. Diabetes Care. 2015;38(11):e182-3. PubMed PMID: 26310693.

17. Hughes J, Vudattu N, Sznol M, Gettinger S, Kluger H, Lupsa B, et al. Precipitation of autoimmune diabetes with anti-PD-1 immunotherapy. Diabetes Care. 2015;38(4):e55-7. PubMed PMID: 25805871.

18. Jaberi-Douraki M, Liu SW, Pietropaolo M, Khadra A. Autoimmune responses in T1DM: quantitative methods to understand onset, progression, and prevention of disease. Pediatr Diabetes. 2014;15(3):162-74. PubMed PMID: 24827702

19. Ansari MJ, Salama AD, Chitnis T, Smith RN, Yagita H, Akiba H, et al. The programmed death-1 (PD-1) pathway regulates autoimmune diabetes in nonobese diabetic (NOD) mice. J Exp Med. 2003;198(1):63-9. PubMed PMID: 12847137.

\section{Ready to submit your research? Choose BMC and benefit from:}

- fast, convenient online submission

- thorough peer review by experienced researchers in your field

- rapid publication on acceptance

- support for research data, including large and complex data types

- gold Open Access which fosters wider collaboration and increased citations

- maximum visibility for your research: over $100 \mathrm{M}$ website views per year

At BMC, research is always in progress.

Learn more biomedcentral.com/submissions 